\title{
Brucella Outer Membrane Proteins to Control Maturation and Antigen Presentation of Mouse Dendritic Cells
}

Ningning Yang

Shihezi University

\section{Zhixia Tong}

Shihezi University

\section{Zhen Wang}

Shihezi University;Key Laboratory of Control and Prevention of Animal Disease,Xinjiang Production and Construction Crops

Mingguo Xu

Shihezi University

Qian Zhang

Xinjiang Academy of Agricultural and Reclamation Science

Huan Zhang

Shihezi University

\section{Yueli Wang}

Shihezi University

Jihai Yi

Shihezi University

Tianhao Sun

Shihezi University

\section{Buyun Cui}

State Key Laboratory of Infectious Disease Prevention and Control,National Institute of Infectious Diseases Control and Prevention,Chinese Center for Disease Contorl and Prevention

Chuangfu Chen ( $\nabla$ chuangfu-chen@163.com )

Shihezi University

\section{Research article}

Keywords: Brucella, Dendritic cells, Outer membrane proteins, Brucella mutants, Antigen presentation

Posted Date: August 31st, 2020

DOI: https://doi.org/10.21203/rs.3.rs-57350/v1 
License: (c) (i) This work is licensed under a Creative Commons Attribution 4.0 International License. Read Full License 
3 Ningning Yang ${ }^{1 \#}$, Zhixia Tong ${ }^{1 \#}$, Zhen Wang ${ }^{1,2 *}$, Mingguo Xu ${ }^{1}$, Qian Zhang ${ }^{3}$, Huan

4 Zhang ${ }^{1}$, Yueli Wang ${ }^{1}$, Jihai Yi ${ }^{1}$, Tianhao Sun ${ }^{1}$, Buyun Cui ${ }^{* *}$, Chuangfu Chen ${ }^{1,5^{*}}$

5 Abstract

6 Background: Brucellosis is a highly contagious zoonotic disease, which seriously

7 endangers animal husbandry in China. Bone marrow-derived dendritic cells (DCs) are

8 professional antigen presenting cells (APC) that play an important role in the interaction

9 between pathogens and host immunity. Because of that DCs play an irreplaceable role in

10 the initiation and orientation of the acquired immune response, establishing the model of

11 interaction between Brucella and DCs may be more suitable than the traditional

12 macrophage model for understanding the relationship between the pathogenic mechanism

13 of Brucella and the specific immune response of the infected host. In this study, DCs were

14 isolated from BALB/C female mice and stimulated with Brucella major outer membrane

15 proteins (OMPs: OMP10, OMP19, OMP25, BP26 and OMP31) or brucella mutants

$16(\Delta o m p 10, \Delta o m p 19, \Delta o m p 25, \Delta b p 26, \Delta o m p 31)$ to examine their effects on DC maturity and

17 antigen presentation.

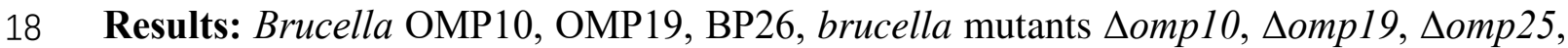

\footnotetext{
*Correspondence: wzhen2018@shzu.edu.cn; cuibuyun6024@sina.com; chuangfu-chen@163.com

${ }^{1}$ College of Animal Science and Technology, Shihezi University, 221 North 4th Road, Shihezi 832000, China

Full list of author information is available at the end of the article
} 
Abp26, $\Delta$ omp31 and Brucella RB51 induced DC maturation and antigen presentation

20 efficiency in mice, activated proliferation of $\mathrm{T}$ lymphocytes, and decreased apoptosis,

21 which helped the host recognize antigens and eliminate pathogens. However, Brucella

$22 \quad 2308$ evaded the host immune function and established chronic infection by maintaining a

23 balance between intracellular replication and inducing apoptosis, thus reducing DC

24 maturation and antigen presentation to T cells. Toll-like receptor (TLR) -mediated signaling

25 pathways were involved in the DC maturation and antigen presentation induced by

26 Brucella OMPs.

27 Conclusion: These results enhance understanding of Brucella pathogenesis and the host

28 protective immune response mechanism and lay the foundation for the rational design of

29 Brucella vaccines.

30 Keywords: Brucella; Dendritic cells; Outer membrane proteins; Brucella mutants; Antigen

31 presentation

\section{Background}

33 Brucellosis is one of the most common zoonotic diseases in the world. This chronic

34 infectious disease can affect the reproductive function of animals and may lead to abortion

35 and infertility, resulting in huge economic losses [1]. Current studies have shown that

36 brucellosis generally does not spread from person to person, however because it can be

37 transmitted via aerosol, there is a high global incidence. Thus, the World Organization for

38 Animal Health (OIE) classifies brucellosis as a class B epidemic disease [2-4] with more

39 than 500,000 people infected each year $[5,6]$. 
The main outer membrane component of Brucella is composed of lipopolysaccharide (LPS) and outer membrane proteins (OMPs). The OMP of Brucella is described as a "complex structure filled by at least 75 proteins" $[7,8]$. In the past 10 years, several kinds of OMPs have been characterized on a molecular level and some studies have been done, however, the research has not been sufficiently depth. Brucella OMPs are the initial contact point between the pathogen and the host immune system and may potentially protect against Brucella infection by inducing cell-mediated immunity $[9,10]$. DCs are considered to be among the most effective antigen-presenting cells in the immune system. They are the only cells that can activate the initial $\mathrm{T}$ lymphocytes, thus triggering the adaptive immune response of the body and are the most effective professional antigen-presenting cell connecting innate immunity and acquired immunity [11-13]. Considering that DCs play an irreplaceable role in the initiation and orientation of the acquired immune response, establishing the model of interaction between Brucella and DCs may be more suitable than the traditional macrophage model for understanding the relationship between the pathogenic mechanism of Brucella and the specific immune response of the infected host. However, several pathogens, including Brucella, have evolved to maintain DCs in a semimature state to escape recognition by the immune system. In vivo studies have shown that Brucella can effectively proliferate in DCs, and in vitro studies have demonstrated that Brucella abortus 2308 and Brucella suis 1330 can inhibit the phenotype maturation of DCs $[14,15]$. In fact, Brucella infection in DCs is characterized by a weak expression of major histocompatibility complex class II (MHC-II) and the costimulatory molecules CD80 and 
61 CD86 on the surface of DCs, leading to the inhibition of the secretion of inflammatory

62 cytokines (TNF- $\alpha$, IL-12), ultimately hampering antigen presentation by DCs to T

63 lymphocytes.

64 The purpose of this study was to investigate the effects of brucella OMPs on the DC

65 maturity and antigen presentation, as well as on innate and acquired immunity, so as to lay

66 a theoretical foundation for the rational design of a brucellosis vaccine and to further

67 understand the pathogenic mechanism of brucellosis and the protective immune response

68 mechanism of the host.

69 Results

70 DC maturation and antigen presentation were affected by OMPs and Brucella

71 mutants

72 Effects of OMPs and Brucella mutants on cell maturation were assessed using flow

73 cytometry. CD40, CD80, CD86, CD83, MHC-I and MHC-II were found to be significantly

74 increased in the OMP10, OMP19, BP26 and Escherichia coli LPS (E-LPS) $(\mathrm{P}<0.01)$, and

75 CD86 and MHC-II were markedly enhanced in Brucella LPSs group(R-LPS: RB51-LPS;

76 S-LPS: 2308-LPS) (P < 0.05), whereas CD40, CD86, MHC-I and MHC-II were obviously

77 decreased in the OMP25 and OMP31 ( $<$ < 0.01) (Fig. 1A) compared with the phosphate-

78 buffered saline(PBS) control group. CD40, CD80, CD86, CD83, MHC-I and MHC-II were

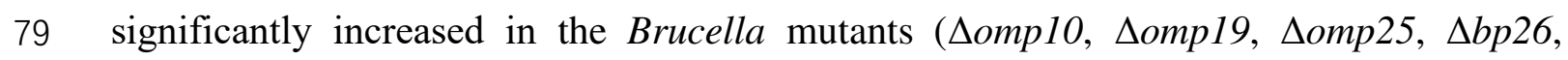

$80 \Delta$ omp31) and Brucella RB51 ( $\mathrm{P}<0.05)$. Finally, the Brucella 2308 significantly inhibited

81 expression of all of these surface markers in DCs $(\mathrm{P}<0.01)$ (Fig. 1B). These results 
demonstrate that Brucella OMPs and Brucella mutants can affect the maturation and

83 antigen presentation of DCs.

The secretion of cytokines was affected by OMPs and Brucella mutants

To analyze the effect of OMPs and Brucella mutants on cytokine secretion, the levels of

86 IL-4, IL-6, IL-10, IL-12, TNF- $\alpha$ and INF- $\gamma$ were measured in the supernatant via ELISA.

87 Compared with the control group, the levels of IL-6, IL-12, INF- $\gamma$ and TNF- $\alpha$ were

dramatically increased in the OMP10, OMP19 and BP26 $(\mathrm{P}<0.01)$, whereas the levels of

IL-4 and IL-10 were significantly decreased in the OMP10, OMP19, BP26 and LPS (P <

0.01). The levels of IL-4 and IL-10 were obviously enhanced in the OMP25 and OMP31

$91(\mathrm{P}<0.05)$, and the levels of IL-6, IL-12 and TNF- $\alpha$ were reduced $(\mathrm{P}<0.05)$ (Fig. 2A). The

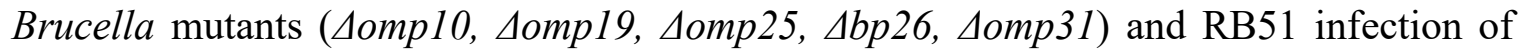

93 DCs significantly induced the secretion of IL-6, IL-10, IL-12 and TNF- $\alpha(\mathrm{P}<0.01)$ and

94 significantly inhibited the secretion of IL-4 and IL-10 $(\mathrm{P}<0.001)$. Brucella 2308 infection

95 significantly inhibited the secretion of IL-6, IL-12 and INF- $\gamma(\mathrm{P}<0.05)$, but significantly increased the secretion of IL-4 and IL-10 (P<0.001) (Fig. 2B). These results show that the cytokine secretion was affected by OMPs and Brucella mutants, these results are consistent with the DC maturation results.

\section{OMPs and Brucella mutants affect the transcription level of TLRs}

RT-PCR was used to determine TLRs mRNA expression. Only the expressions of TLR2 and TLR4 were enhanced significantly in OMPs $(\mathrm{P}<0.05)$ (Fig. 3A), whereas the 
Brucella mutants $(\mathrm{P}<0.05)$ (Fig. 3B). It has been suggested that TLR-mediated signaling pathways play a synergistic role in the maturation and antigen presentation of DCs.

\section{MTT}

MTT colorimetric assay was used to measure T cell viability. Compared with the PBS group, DCs stimulated by OMP10, OMP19 and BP26 enhanced T lymphocyte proliferation more effectively, whereas DCs stimulated by OMP25 and OMP31 inhibited T cell proliferation (Fig. 4A). In addition, the proliferation efficiency of T cells in each group was the highest when the ratio of DCs: T cells was 1: 50. DC infection with brucella mutants and RB51 was more effective, and the proliferation efficiency was the most significant

112 when the ratio of DCs: T cells was 1:25 (Fig. 4B). These results suggest that the

113 proliferation efficiency of T cells stimulated by DCs is related to the antigen-presenting

114 ability of DCs and the concentration of T cells.

\section{Brucella mutants can induce apoptosis of DCs}

116 The effect of Brucella mutants on apoptosis of DCs were detected by flow cytometry.

117 Compared with the PBS control group, the apoptosis level of DCs was dramatically 118 increased in the Brucella mutants, Brucella 2308 and RB51 groups $(\mathrm{P}<0.001)$ (Fig. 5A).

119 The apoptosis rates were shown in the Fig.5B. The results show that apoptosis is increased 120 after stimulation of DCs with Brucella mutants and brucella RB51 and 2308.

Brucella mutants decreased Brucella survival and replication in DCs

122 DCs were infected with Brucella and Brucella mutants and the survival capacity and replication capability of the Brucella in the DCs were determined. The DCs were infected 
with the seven strains at a MOI of 5, and the number of surviving bacteria was calculated.

At $1 \mathrm{~h}$ post-infection, there was an overall decrease in the number of bacteria in DCs that

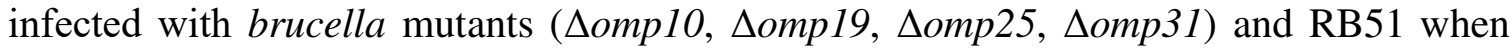
compared with DCs that infected with 2308. However, at $6 \mathrm{~h}$ post-infection, only the

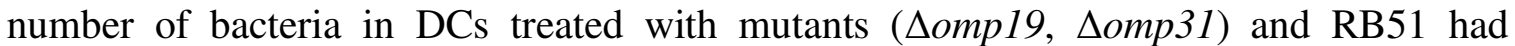
decreased when compared with 2308. At $12 \mathrm{~h}$ post-infection bacteria number in DCs that

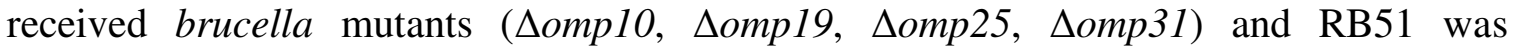
significantly lower compared to DCs that infected with 2308 . At 24 h post-infection, there was an overall significant decrease in the number of bacteria in DCs that infected with brucella mutants $(\Delta o m p 19, \Delta o m p 25, \Delta o m p 31)$ and RB51 when compared with DCs that infected with 2308 . Finally, at 48 h post-infection, there was all significant decrease in the number of bacteria in DCs that infected with brucella mutants $(\Delta o m p 19, \Delta o m p 26)$ and RB51 compared with DCs that infected with 2308 (Fig.6). These results suggest that the survival and replication ability of Brucella is decreased by Brucella mutants in DCs.

\section{Discussion}

In this study, the effects of Brucella OMPs and Brucella mutants on the maturation and antigen presentation of DCs were evaluated. DCs were stimulated with Brucella OMPs and Brucella mutants and expression of the co-stimulatory molecule was assessed to investigate DC maturation and antigen presentation. The levels of cytokines in the supernatant were measured and the ability of DCs to shift $\mathrm{T}$ lymphocyte proliferation and differentiation was assessed, as well as mRNA expression levels of transcription factors TLR2, TLR4 and 
TLR9. DCs were stimulated by Brucella and Brucella mutants to evaluate the rate of apoptosis and intracellular survival in DCs. These results indicate that Brucella OMPs and Brucella mutants affect the maturation and antigen presentation of DCs.

DCs have the ability to express various pathogens recognition receptors (PRRs), which enable them to quickly sense stimulation by invasive pathogens and initiate an innate immune response [16]. However, DCs have established a special, adjustable phagocytic pathway, mainly by initiating antigen-specific immune responses to foreign antigens that destroy tissues and maintaining tolerance to self-antigens [17]. Over the past 10 years, DCs have been proven to be the key cell group determining the starting point of the specific immune response [18]. Moreover, when mature DCs present antigens to the initial T lymphocytes and stimulate their proliferation, they also induce the subsequent polarization of the adaptive immune response to the distribution of Th1 and Th 2 cells by secreting different cytokines. For example, IL-4 stimulates initial T lymphocytes to differentiate into Th2 cells and regulates the humoral immune response [19,20]. IL-10 not only inhibits the expression of MHC-II molecules and co-stimulatory molecules, including CD40, CD80 and CD86, on the surfaces of macrophages and DCs but also inhibits the secretion of inflammatory cytokines (TNF- $\alpha$, IL-12), thus inhibiting cellular antigen presentation [21]. Recent studies have found that Brucella regulates TNF- $\alpha$ secretion through an OMP25dependent mechanism, inhibits DCs maturation and IL-12 secretion, and inhibits initial T cell activation and antigen presentation, thus inducing chronic infection [15]. It has been found that several Brucella proteins, including lipoprotein OMP19 [9], Brucella Lumazine 
synthase (BLS) [22], OMP16 [23], and BvrR [24] can induce DC maturation. These

Brucella proteins may interact with DCs through an O antigen-independent pathway. In the

current study, it was found that Brucella OMPs (OMP10, OMP19, BP26), Brucella mutants

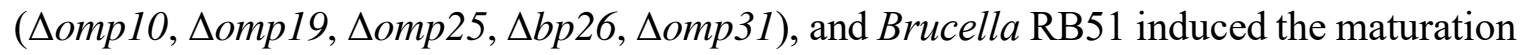

and antigen presentation of DCs and improved activation of T lymphocyte proliferation,

which is beneficial for recognizing antigens and eliminating pathogens, whereas Brucella

2308 reduced the DC maturation and antigen presentation to $\mathrm{T}$ cells by maintaining the

balance between intracellular replication and inducing apoptosis, thus escaping the immune

function of the host and establishing chronic infection.

In this study, the signal pathway mediated by toll-like receptors (TLRs) were found to be

involved in the maturation and antigen presentation of DCs induced by Brucella OMPs and

Brucella mutants. DC activation and maturation were initiated by recognition of pathogen-

related molecular patterns (PAMP) and TLRs [15]. TLRs transduce signals through

common junction molecules to stimulate DCs to secrete inflammatory factors [12]. Studies

have shown that Brucella transduces signals through TLR2, TLR4 and MyD88 [25]. As

clearance of Brucella by MyD88 is very important, it may be that TLR9 (also signal

transduced through MyD88) plays a major role in the interaction between DCs and

Brucella [15]. Zwerdling [26] et al also demonstrated that Brucella transduces signals

through TLR2 and TLR4 in DCs. Oliveira [27] and Huang [28] et al demonstrated the

crucial role of TLR9 in DC-mediated IL-12 secretion and Brucella clearance. 
whereas the 2308 strain inhibits apoptosis [29]. However, the current study found that Brucella RB51 and 2308, as well as the Brucella mutants induced apoptosis, and that Brucella 2308 induced a significantly higher level of apoptosis. The Brucella 2308 induced apoptosis at different status in macrophages and DCs, which may be related to the different immune types induced by the two host cells and the different interactions between Brucella and the two host cells [30]. Macrophages are full-time phagocytes that engulf and remove exogenous antigens and can expose antigens to the extracellular environment and facilitate host clearance of Brucella [31]. DCs are the main antigen-presenting cells, which process antigens and presents them to the surface of other cells in the immune system. Studies have demonstrated that apoptotic cells themselves can inhibit inflammation by sending inhibitor signals to DCs. Moreover, internalization of apoptotic cells don't induce DCs maturation but maintains DCs in a semi-mature state [21]. Immature DCs migrate constitutively from the periphery to the lymphoid organs and present self-antigens to induce $\mathrm{T}$ cell tolerance.

200 Studies have shown that DCs downregulate the expression of chemokine receptor CCR5 201 after uptake of apoptotic cells and up-regulation of CCR7 expression, thus transforming 202 from inflammatory cytokines to lymphoid chemokines, resulting in DCs homing to 203 draining lymph nodes [32]. After uptake of apoptotic cells, DCs not only maintain an 204 immature phenotype but also secrete TGF- $\beta 1$, which lead to the induction of regulatory T cell immunosuppression [21,33]. Therefore, DCs play an important role in the host immune response to pathogens and maintenance of tissue tolerance.

\section{Conclusion}


In summary, these results show that Brucella OMPs (OMP10, OMP19, BP26, OMP25, in the regulation of DC maturation and antigen presentation. The above results can contribute to the rational design of vaccines against Brucella and a better understanding of the pathogenesis of Brucella and the protective immune response in the host. However, in

213 vivo studies are needed on the specific mechanisms through which Brucella affects the 214 maturation of DCs, the efficiency of antigen presentation and the stimulation of T cell 215 proliferation.

\section{Methods}

\section{Mice}

218 All the experimental procedures involving animals were approved by the Animal 219 Experimental Ethical Committee Form of the First Affiliated Hospital of Medical College, 220 Shihezi University. Ethical Committee Approval Notice No. A 280-167. Specific pathogen 221 free Female BALB/C mice, 6-8 weeks old with mean BW of $20 \pm 5 \mathrm{~g}$ were purchased from 222 the Animal Experiment Center of Xinjiang Medical University, and kept in a cage and 223 sterilized wood dust as the bedding material. All of mice were given enough food and water, 224 a $12 \mathrm{~h}$ light-dark cycle and $15-20{ }^{\circ} \mathrm{C}, 50 \%$ relative humidity.

\section{Bacteria}

226 B. abortus 2308, B. abortus RB51(CDC, China), brucella PET-30a-omp10, PET-28aomp19, PET-28a-omp25, PET-28a-bp26, PET-30a-omp31 the prokaryotic recombinant 
229

230

231

232

233

234

235

236

237

238

239

240

241

242

243

244

245

246

247

248

249

were all constructed by the zoonotic laboratory of Shihezi University. Each bacterial strain

was cultured in tryptone soya agar (TSA) (Becton, Dickinson and Company, USA).

\section{Isolation and cultivation of DCs}

The mouse DC isolation method of Inaba [34-36] et al was used in this study. Briefly, cells were flushed and purified from the tibias and femurs of BABL/C mice (every time 10 mice), which had been euthanized by cervical dislocation. The cells were plated at $1 \times 10^{6} /$ well in $2 \mathrm{~mL}$ of RPMI 1640 and then cultured at $37{ }^{\circ} \mathrm{C}$ in $5 \% \mathrm{CO}_{2}$ for $3 \mathrm{~h}$. The supernatant was then discarded to remove non-adherent cells, and fresh $10 \%$ fetal bovine serum (10\% FBS) with GM-CSF (10 ng/mL) and IL 4 (10 ng/mL) (all PeproTech, USA) were added. Fresh medium was added on days 2 and 4 and cells were collected on day 6 .

\section{Flow cytometry analysis}

DCs treated with OMPs and Brucella mutants were analyzed via flow cytometry for expression of multiple markers of maturation on the cells surface. The following antibodies and appropriate isotype controls (all BD Biosciences, USA) were utilized. DCs were stimulated by purified OMPs (50 ug/mL) (endotoxin removed), Brucella LPS groups (RLPS, S-LPS) (1 ug/mL), Escherichia coli (E.coli) LPS (E-LPS) (1 ug/mL), or Brucella mutants at a multiplicity of infection (MOI) of 5, PBS was used as a control. After $24 \mathrm{~h}$, the cells were collected and washed three times and the cell concentration was adjusted to $1 \times 10^{6}$ cells/tube using PBS. All antibodies (PE-anti-mouse CD11c, PE-anti-mouse CD80, PE-anti-mouse CD83, PE-anti-mouse CD86 and PE-anti-mouse CD40 ( $1 \mu \mathrm{L} /$ tube)) were added to each tube. The DCs and antibodies were mixed and incubated at $4^{\circ} \mathrm{C}$ for 20 
minutes and then washed three times and the unbound antibodies were removed. The cells

were resuspended in PBS $(300 \mathrm{~mL})$ and cell phenotype changes were detected by flow

cytometry [14,37]. Data were collected on a FACSCalibur (BD Biosciences) and analyzed

253 using FlowJo software (Tree Star).

\section{Cytokine detection}

255 Cytokine measurements [9,21] were done at $24 \mathrm{~h}$. The cell culture supernatant was 256 collected and the expression of cytokines TNF- $\alpha$, IFN- $\gamma$, IL-6, IL-12, IL-10 and IL-4 were 257 quantified according to ELISA kit instructions (BD Biosciences).

\section{Quantitative real-time PCR}

259 Expression of transcriptional factors including TLR2, TLR4 and TLR9 mRNA were 260 evaluated using real-time PCR (RT-PCR). Briefly, the total RNA(1 $\mu \mathrm{g})$ was extracted using 261 TRIzol reagent and reverse transcribed to synthesize cDNA (Kangwei, China). The standard curve was drawn for the genes from cDNA. GADPH was used as the endogenous control and specific primers for this gene were designed using Primer 5 software (Table 1).

264 Comparative RT-PCR (Takara, Japan) was performed using SYBR Green Supermix via an RT-PCR machine (RocheLightCycler480, Germany). Finally, TLR2, TLR4 and TLR9 relative expressions were determined using the equation 2- $\Delta \mathrm{CT}[38,39]$. 
Table 1 Primers and sequences of TLRs

\begin{tabular}{lc}
\hline Primer & Primer sequences (5'-3') \\
\hline TLR-2-F & GCGACATCCATCACCTGACTCTTC \\
TLR-2-R & GCCTCGGAATGCCAGCTTCTTC \\
TLR-4-F & CACAGAAGAGGCAAGGCGACAG \\
TLR-4-R & GACTGGCACTAACCACATAGAGAACTG \\
TLR-9-F & ACCTCAGCCACAACATTCTCAAGAC \\
TLR-9-R & TGCCACACTTCACACCATTAGCC \\
\hline
\end{tabular}

279

280 Cell viability assay

281 DCs (day 6) were collected and the cells were stimulated with OMPs and Brucella mutants.

282 After $48 \mathrm{~h}$, the stimulated cells were collected and the concentration was adjusted to $1 \times$ $28310^{5}$ cells $/ \mathrm{mL}$ in RPMI-1640 medium. The negative and positive control groups were given 284 the same treatments. The cells were mixed with mitomycin $\mathrm{C}(25 \mu \mathrm{g} / \mathrm{mL})$ and incubated 285 for $30 \mathrm{~min}$ at $37^{\circ} \mathrm{C}$. Cells were then placed into a 96-well cell culture plate $(100 \mu \mathrm{L}$ per 286 well) as stimulating cells. Mouse spleen lymphocytes were prepared using a Solebo mouse 287 spleen lymphocyte separation kit (Solebo, China). The cells were obtained, the 288 concentration was adjusted to $5.0 \times 10^{6}$ cells/well, and $5.0 \times 10^{4}$ cells were added to each 289 well of the 96-well cell culture plate as reactive cells. The ratios of stimulated cells to 290 reactive cells were 1:25, 1:50 and 1: 100, with three wells for each ratio. After $72 \mathrm{~h}$, MTT $291(20 \mu \mathrm{L})$ was added to each well, and the cells were incubated for $4 \mathrm{~h}$. The intracellular 
punctate particles were observed under microscope. The supernatant was discarded and DMSO $(100 \mu \mathrm{L})$ was added to each well and the plate was incubated in the dark for about

4 h. After the purple crystal was completely dissolved under the microscope, the $\mathrm{OD}_{570 \mathrm{~nm}}$ value was detected. The stimulation index $(\mathrm{SI})=\mathrm{OD}$ value of stimulated group/OD value of control group [40-42]. The experiment was repeated four times.

\section{Apoptosis detection}

298 The Annexin V-FITC apoptosis assay kit (Absin Bioscience Inc, China) was used to 299 evaluate the rate of apoptosis in DCs. DCs $\left(5 \times 10^{5}\right.$ cells $)$ were infected with Brucella and 300 Brucella mutants at a MOI of 5. After $24 \mathrm{~h}$, DCs were collected and were washed three times with PBS. A $100 \mu \mathrm{L}$ volume of the binding buffer was added to each tube to resuspend the cells. Annexin V-FITC ( $5 \mu \mathrm{L})$ was added to the binding buffer, the solution was mixed well, and the tubes were incubated for $15 \mathrm{~min}$ in the dark at room temperature. Propidium iodide $(5 \mu \mathrm{L})$ was added and the solution mixed well 5 min prior to flow cytometry. Binding buffer $(200 \mu \mathrm{L})$ was then added to each tube and the cell apoptosis assay was performed using the flow cytometry apparatus (BD). Each experiment was performed three times $307 \quad[43,44]$

\section{Intracellular survival}

309 DCs were infected with Brucella and Brucella mutants at a MOI of 5. At 45 min, DCs were washed three times with PBS and then incubated with $50 \mu \mathrm{g} / \mathrm{mL}$ gentamicin (Invitrogen

311 Life Technologies, USA) for $1 \mathrm{~h}$ to kill the remaining extracellular bacteria. DCs were 
313 collected after 1, 6, 12, 24 and $48 \mathrm{~h}$ of infection. DCs were then washed three times, 5 min

314 each time, with PBS and then cleaved with TritonX-100 (0.1\%). After continuous gradient

315 dilution to a suitable concentration, $100 \mu \mathrm{L}$ lysate was used to coat a TSB Agar Brucella

316 plate (three repeated controls for each dilution) and cultured (inverted) at $37^{\circ} \mathrm{C}$ in a $5 \%$

$317 \mathrm{CO}_{2}$ incubator for 3-4 days to determine the number of CFU (CFU/well) [45].

\section{Statistical analysis}

319 Data are presented as mean \pm standard deviation and were analyzed using Graph Pad Prism

320 software (Graph-Pad Software Inc, San Diego, CA, USA). The differences groups were

321 analyzed by the analysis of variance using SPSS 17.0 software (SPSS, Inc. Chicago, IL,

322 USA). A P-value of $<0.01$ was considered greatly significant, and a $\mathrm{P}$-value of $<0.05$ was

323 considered significant. $* * * \mathrm{P}<0.001$. All experiments were independently performed at $324 \quad$ least three times.

\section{Abbreviations}

326 Major histocompatibility complex class I/II: MHC-I/MHC-II; 2308: B. abortus 2308;

327 RB51: B. abortus RB51; OMPs: Outer member proteins; DCs: Dendritic cells; LPS:

328 lipopolysaccharide; R-LPS: RB51-LPS; S-LPS: 2308-LPS; Escherichia coli LPS: E-LPS;

329 PBS: phosphate-buffered saline.

\section{Declarations}

\section{Acknowledgments}

332 This study was supported by grants from National Natural Science Foundation of China

333 (No. U1803236;31760020), Major scientific and technological projects of the Corps (No. 
2017AA003) and Shihezi University Youth Innovative Talent Cultivation Program (No.

CXPY201909). We thank LetPub (www.letpub.com) for its linguistic assistance during the preparation of this manuscript. We are all grateful to the reviewers for their invaluable comments to improve this manuscript.

Authors' contributions

$339 \mathrm{NY}, \mathrm{BC}, \mathrm{CC}$ and ZW designed the project. NY, ZW and ZT performed the experiments.

$340 \mathrm{NY}, \mathrm{ZW}, \mathrm{ZT}$ and MX contributed to writing the manuscript. MX, QZ, HZ, YW, YJ and TS

341 contributed to isolated cells and data analysis. All authors have read and approved the final

342 manuscript.

\section{$343 \quad$ Funding}

344 National Natural Science Foundation of China (No. U1803236;31760020), Major scientific 345 and technological projects of the Corps (No. 2017AA003) and Shihezi University Youth

346 Innovative Talent Cultivation Program (No. CXPY201909). The fund (No.

347 U1803236;31760020) mainly supports the buy and feed mice, and all expenses incurred in 348 carrying out animal experiments; the fund (No. 2017AA003) mainly supports the all 349 reagents and consumables. the fund (No. CXPY201909) mainly supports sampling and 350 labor expenses, and analysis and testing expenses.

$351 \quad$ Availability of data and materials

352 The data used or analyzed in this study are available from the corresponding author on 353 reasonable request.

\section{Ethics approval and consent to participate}


355 All the experimental procedures involving animals were approved by the Animal

356 Experimental Ethical Committee Form of the First Affiliated Hospital of Medical College,

357 Shihezi University. Ethical Committee Approval Notice No. A 280-167

\section{Consent for publication}

359 Not applicable.

\section{Competing interests}

361 The authors declare that there is no conflict of interest in this study.

\section{Author details}

$363 \quad$ EEqual contributors. ${ }^{1}$ College of Animal Science and Technology, Shihezi University, 221

364 North 4th Road, Shihezi 832000, China; ${ }^{2}$ Key Laboratory of Control and Prevention of 365 Animal Disease, Xinjiang Production \& Construction Corps, Shihezi 832000, China; ${ }^{3}$ State 366 Key Laboratory for Sheep Genetic Improvement and Healthy Production, Xinjiang 367 Academy of Agricultural and Reclamation Science, Shihezi 832000, China; ${ }^{4}$ State Key 368 Laboratory of Infectious Disease Prevention and Control, National Institute of Infectious 369 Diseases Control and Prevention, Chinese Center for Disease Control and Prevention, 370 Beijing 102206, China; ${ }^{5}$ Co-Innovation Center for Zoonotic Infectious Diseases in the 371 western region, Shihezi 832000, China.

\section{$372 \quad$ References}

373 [1] D"Anastasio R, Staniscia T, Milia M L, et al. Origin, evolution and paleoepidemiology 374 of brucellosis. Epidemiology \& Infection. 2011;139(01):149-156.

375 https://doi.org/10.1017/S095026881000097X.

376 [2] Atluri VL, Xavier MN, de Jong M F, et al. Interactions of the Human Pathogenic 
Brucella Species with Their Hosts. Annual Review of Microbiology. 2011;65(1):523-541. https://doi.org/10.1146/annurev-micro-090110-102905.

[3] Kato Y, Masuda G, Itoda I, et al. Brucellosis in a Returned Traveler and His Wife:

Probable Person-To-Person Transmission of Brucella melitensis. Journal of Travel Medicine. 2007;14(5):343-345. https://doi.org/10.1111/j.1708-8305.2007.00139 x.

[4] Godfroid J, Scholz HC, Barbier T, et al. Brucellosis at the animal/ecosystem/human interface at the beginning of the 21 st century. Preventive Veterinary Medicine. 2011;102(2):118-131. https://doi.org/10.1016/j.prevetmed.2011.04.007.

[5] Pappas G, P. anagopoulou P, Christou L, et al. Brucella as a biological weapon. Cellular

\& Molecular Life Sciences Cmls. 2006;63(19-20):2229. https://doi.org/10.1007/s00018006-6311-4.

[6] Figueiredo P D, Ficht T A, Rice-Ficht A, et al. Pathogenesis and Immunobiology of

Brucellosis Review of Brucella-Host Interactions. American Journal of Pathology.

391 [7] Huang LY, Krieg AM, Eller N, et al. Induction and Regulation of Th1-Inducing 392 Cytokines by Bacterial DNA, Lipopolysaccharide, and Heat-Inactivated Bacteria. Infection \& Immunity. 1999;67(12):6257. https://doi.org/10.1111/j.1574-695X.1999.tb01403.x.

[8] Berman, D.T, Kurtz, R.S. Relationship of biological activities to structures of Brucella abortus endotoxin and LPS. Annales de l'Institut Pasteur / Microbiologie. 1987;138(1):98- 
398 Adjuvant for Vaccine Formulations against Salmonella Infection in Mice. Frontiers in

399 Immunology. 2017;8(3):171. https://doi.org/10.3389/fimmu.2017.00171.

400 [10] Yousefi S, Tahmoorespur M, Sekhavati MH. Cloning, expression and molecular 401 analysis of Iranian Brucella melitensis Omp25 gene for designing a subunit vaccine.

402 Research in Pharmaceutical Sciences. 2016;11(5):412-418. https://doi.org/10.4103/1735$403 \quad 5362.192493$

404 [11] Izabela, P, Klaska, et al. Lipopolysaccharide-primed heterotolerant dendritic cells 405 suppress experimental autoimmune uveoretinitis by multiple mechanisms. Immunology. 406 2016. https://doi.org/10.1111/imm.12691.

407 [12] Nagai Y, Garrett KP, Ohta S, et al. Toll-like Receptors on Hematopoietic Progenitor 408 Cells Stimulate Innate Immune System Replenishment. Immunity, 2006;24(6): 801-812. 409 https://doi.org/10.1016/j.immuni.2006.04.008.

410 [13] Langhorne J, Albano F R, Hensmann M, et al. Dendritic cells, pro-inflammatory 411 responses, and antigen presentation in a rodent malaria infection. Immunological Reviews. 412 2010;201(1):35-47. https://doi.org/10.1111/j.0105-2896.2004.00182. x.

413 [14] Billard E, Dornand J, Gross A. Brucella suis Prevents Human Dendritic Cell 414 Maturation and Antigen Presentation through Regulation of Tumor Necrosis Factor Alpha 415 Secretion. Infection \& Immunity. 2007;75(10):4980-4989. 416 https://doi.org/10.1128/IAI.00637-07.

417 [15] Salcedo SP, Marchesini MI, Lelouard H, et al. Brucella control of dendritic cell 418 maturation is dependent on the TIR-containing protein Btp1. Plos Pathogens. 2008;4(2): 
419

420

421

422

423

424

425

426

427

428

429

430

431

432

433

434

435

436

437

438

439

e21. https://doi.org/10.1371/journal.ppat.0040021.

[16] Amigorena S, Savina A. Intracellular mechanisms of antigen cross presentation in dendritic cells. Current Opinion in Immunology. 2010;22(1):109. https://doi.org/10.1016/j.coi.2010.01.022.

[17] Steinman RM, Turley S, Mellman I, et al. The induction of tolerance by dendritic cells that have captured apoptotic cells. Journal of Experimental Medicine. 2000;191(3):411. https://doi.org/10.1084/jem.191.3.411.

[18] Tam MA, Rydström A, Sundquist M, et al. Early cellular responses to Salmonella infection: dendritic cells, monocytes, and more. Immunological Reviews. 2008;225 (1):140-162. https://doi.org/10.1111/j.1600-065X.2008.00679.x.

[19] Spörri R, Sousa CRE. Inflammatory mediators are insufficient for full dendritic cell activation and promote expansion of $\mathrm{CD}^{+} \mathrm{T}$ cell populations lacking helper function. Nature Immunology. 2005;6(2):163-170. https://doi.org/10.1038/ni1162.

[20] Alloatti A, Kotsias F, Pauwels AM, et al. Toll-like Receptor 4 Engagement on Dendritic Cells Restrains Phago-Lysosome Fusion and Promotes Cross-Presentation of Antigens. Immunity. 2015;43(6):1087. https://doi.org/10.1016/j.immuni.2015.11.006.

[21] Contractor N, Louten J, Kim L, et al. Cutting Edge: Peyer's Patch Plasmacytoid Dendritic Cells (pDCs) Produce Low Levels of Type I Interferons: Possible Role for IL-10, TGF $\beta$, and Prostaglandin E2 in Conditioning a Unique Mucosal pDC Phenotype. Journal of Immunology. 2007;179(5):2690-4. https://doi.org/10.4049/jimmunol.179.5.2690. [22] Clausse M, Díaz, Alejandra G, Ghersi G, et al. The vaccine candidate BLSOmp31 
440 protects mice against Brucella canis infection. Vaccine. 2013;31(51):6129-6135.

441 https://doi.org/10.1016/j.vaccine.2013.07.041.

442 [23] Tibor A, Decelle B, Letesson JJ. Outer membrane proteins Omp10, Omp16, and

443 Omp19 of Brucella spp. are lipoproteins. Infection \& Immunity. 1999;67(9):4960-2.

444 https://doi.org/10.1111/j.1574-695X.1999.tb01365. x.

445 [24] Solalanda A, Pizarrocerdá J, Grilló MJ, et al. A two-component regulatory system

446 playing a critical role in plant pathogens and endosymbionts is present in Brucella abortus

447 and controls cell invasion and virulence. Molecular Microbiology. 1998;29(1):125.

448 https://doi.org/10.1046/j.1365-2958.1998.00913. x.

449 [25] Sengupta D, Koblansky A, Gaines J, et al. Subversion of Innate Immune Responses

450 by Brucella through the Targeted Degradation of the TLR Signaling Adapter, MAL Journal

451 of Immunology. 2010;184(2):956-964. https://doi.org/10.4049/jimmunol.0902008.

452 [26] Zwerdling A, Delpino MV, Barrionuevo P, et al. Brucella lipoproteins mimic dendritic

453 cell maturation induced by Brucella abortus. Microbes \& Infection. 2008;10(12-13): 1346-

454 1354. https://doi.org/10.1016/j.micinf.2008.07.035.

455 [27] Oliveira SC, Oliveira FSD, Macedo GC, et al. The role of innate immune receptors in 456 the control of Brucella abortus infection: Toll-like receptors and beyond. Microbes \&

457 Infection. 2008;10(9):1005-1009. https://doi.org/10.1016/j.micinf.2008.07.005.

458 [28] Huang LY, Reise SC, Itoh Y, et al. IL-12 induction by a TH1-inducing adjuvant in vivo:

459 dendritic cell subsets and regulation by IL-10. Journal of Immunology. 2001;167(3): 1423- 
461

462

463

464

465

466

467

468

469

470

471

472

473

474

475

476

477

478

479

480

481

[29] Goel D, Rajendran V, Ghosh P C, et al. Cell mediated immune response after challenge

in Omp25 liposome immunized mice contributes to protection against virulent Brucella

abortus 544. Vaccine. 2013;31(8):1231-1237.

https://doi.org/10.1016/j.vaccine.2012.12.043.

[30] Steinman RM, Shannon T, Ira M, et al. The Induction of Tolerance by Dendritic Cells

That Have Captured Apoptotic Cells. Journal of Experimental Medicine. 2000;191(3):411. https://doi.org/10.1084/jem.191.3.411.

[31] Cluff CW, Ziegler HK. An early response to lipopolysaccharide is the elicitation of macrophages specialized for antigen degradation with negative regulatory effects on the induction of specific immune responses. Infection \& Immunity. 1987;55(6):1346.

https://doi.org/10.2516/ogst/2009037.

[32] LB, GI P, G M, et al. Defects in regulation of apoptosis in caspase-2-deficient mice.

Genes \& Development.1998;12(9):1304-1314. https://doi.org/10.1101/gad.12.9.1304.

[33] Van Engeland M, Ramaekers FCS, Schutte B, et al. A novel assay to measure loss of plasma membrane asymmetry during apoptosis of adherent cells in culture. Cytometry. 2015;24(2):131-139. https://doi.org/10.1002/(SICI)1097-0320(19960601)24:2<131::AID-

\section{CYTO5>3.0.CO;2-M.}

[34] Inaba K, Inaba M, Romani N, et al. Generation of large numbers of dendritic cells from mouse bone marrow cultures supplemented with granulocyte/macrophage colonystimulating factor. Journal of Experimental Medicine. 1992;176(6): 1693-1702. https://doi.org/10.1084/jem.176.6.1693. 
482 [35] Wang W, Li J, Wu K, et al. Culture and Identification of Mouse Bone Marrow-Derived

483 Dendritic Cells and Their Capability to Induce T Lymphocyte Proliferation. Medical

484 science monitor: international medical journal of experimental and clinical research. 2016;

485 22:244-250. https://doi.org/10.12659/MSM.896951

486 [36] Boes M, Bertho N, Cerny J, et al. T Cells Induce Extended Class II MHC

487 Compartments in Dendritic Cells in a Toll-Like Receptor-Dependent Manner. Journal of

488 Immunology. 2003; 171(8):4081-4088. https://doi.org/10.4049/jimmunol.171.8.4081.

489 [37] Wagner C S, Jeff G, Peter C, et al. Intracellular Regulation of Cross-Presentation

490 during Dendritic Cell Maturation. Plos One. 2013;8(10): e76801. https://doi.org/

491 10.1371/journal.pone.0076801.

492 [38] Yousef, Nikmanesh, Mohammad, et al. Improved Function and Maturation of

493 Dendritic Cells Stimulated by Recombinant pp65 Protein: An in-vitro Design. Iranian

494 Journal of Immunology Iji. 2019. https://doi.org/10.22034/IJI.2019.39403.

495 [39] Jin Y Y, Wang X, Du J, et al. Epstein-Barr virus induces the differentiation of semi-

496 mature dendritic cells from cord blood monocytes. Human Immunology. 2014;75(4):306-

497 316. https://doi.org/10.1016/j.humimm.2014.02.002.

498 [40] Bordbar N, Karimi M H, Amirghofran Z. Phenotypic and functional maturation of 499 murine dendritic cells induced by 18 alpha- and beta-glycyrrhetinic acid.

500 Immunopharmacology \& Immunotoxicology. 2013;36(1):52.

501 https://doi.org/10.3109/08923973.2013.864670

502 [41] Morelli A E, Larregina A T, Ganster R W, et al. Recombinant Adenovirus Induces 
Maturation of Dendritic Cells via an NF-kappa B-Dependent Pathway. Journal of Virology. 2000; 74(20):9617-9628. https://doi.org/10.1128/JVI.74.20.9617-9628.2000.

[42] Marino M W, Dunn A, Grail D, et al. Characterization of tumor necrosis factor-

deficient mice. Proceedings of the National Academy of Sciences. 1997;94(15):8093-8098. https://doi.org/10.1073/pnas.94.15.8093.

[43] Ni B, Bai F F, Wei Y, et al. Apoptosis induced by lipid-associated membrane proteins

509 from Mycoplasma hyopneumoniae in a porcine lung epithelial cell line with the 510 involvement of caspase 3 and the MAPK pathway Genetics \& Molecular Research Gmr. $5112015 ; 14(3): 11429$. https://doi.org/10.4238/2015.September.25.10.

512 [44] Lis N Velásquez, Delpino M V, Andrés E Ibaez, et al. Brucella abortus induces 513 apoptosis of human T lymphocytes. Microbes and Infection. 2012;14(7-8):639-650. 514 https://doi.org/10.1016/j.micinf.2012.02.004.

515 [45] Li Z, Zhang J, Zhang K, et al. Brucella melitensis $16 \mathrm{M} \Delta \mathrm{TcfSR}$ as a potential live 516 vaccine allows for the differentiation between natural and vaccinated infection. 517 Experimental \& Therapeutic Medicine. 2015. https://doi.org/10.3892/etm.2015.2619.

518 Fig. 1 The effects of Brucella major OMPs and Brucella on surface molecule expression 519 in DCs. DCs were cultured by purified outer membrane proteins (OMPs: OMP10, OMP19, 520 OMP25, BP26, and OMP31) (endotoxin removed), R-LPS, S-LPS, E-LPS(A), or Brucella

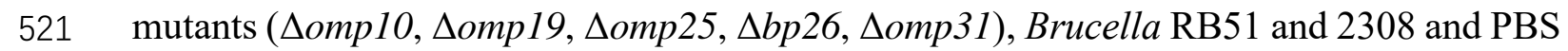
522 for $24 \mathrm{~h}$ (B). DCs were harvested and analyzed by flow cytometry. Cells were stained with 523 fluorescent antibodies against CD80, CD83, CD86, CD40, MHC-I and MHC-II. On the 
left is a histogram of the presented fluorescence as measured by flow cytometry, and on the

right is a histogram of the mean fluorescence intensity (MFI) obtained by statistical

analysis. The data are representative of three independent experiments. ${ }^{*} \mathrm{P}<0.05, * * \mathrm{P}<$

0.01, and ***P $<0.001$. R-LPS: RB51-LPS; S-LPS: 2308-LPS; Escherichia coli LPS: E-

LPS; phosphate-buffered saline: PBS.

Fig. 2 Cytokine secretion in supernatants of DCs infected with OMPs and Brucella mutants.

530 DCs were cultured with purified OMPs (endotoxin removed), R-LPS, S-LPS, E-LPS (A),

531 or Brucella mutants, Brucella RB51, 2308 and PBS for 24 h (B), The culture supernatant

532 was collected and the levels of secreted cytokines IL-4, IL-6, IL-10, IL-12, TNF- $\alpha$ and

533 IFN- $\gamma$ quantified by ELISA. Data shown are the means \pm SEMs of three separate

534 experiments. Significance was calculated using the t-test. $* \mathrm{P}<0.05, * * \mathrm{P}<0.01$ and $* * *$

$535 \mathrm{P}<0.001$.

536 Fig. 3 Effects of OMPs and Brucella mutants on transcription of TLRs mRNA in DCs. DCs

537 were stimulated by OMPs, R-LPS, S-LPS, E-LPS (A), and Brucella mutants, Brucella

538 RB51 and 2308 (B) for $24 \mathrm{~h}$. DCs were then collected, and total RNA was extracted for

539 RT-PCR detection of TLR-2, TLR-4 and TLR-9 mRNA transcription levels. Statistical

540 analysis was performed by the $2-\Delta \mathrm{CT}$ method. Experiments were performed three times in

541 duplicate. $* \mathrm{P}<0.05, * * \mathrm{P}<0.01$, and $* * * \mathrm{P}<0.001$.

542 Fig. 4 Effects of OMPs and Brucella mutant-stimulated DCs on T lymphocyte proliferation.

543 DCs were stimulated with OMPs, R-LPS, S-LPS, E-LPS (A), or Brucella mutants, Brucella

544 RB51 and 2308 (B) for $24 \mathrm{~h}$, mixed with naive $\mathrm{T}$ cells and incubated at different 
concentrations $(1: 25,1: 50,1: 100)$ for $72 \mathrm{~h}$. The proliferation efficiency of $\mathrm{T}$ lymphocytes

546 in each group was examined. Each experiment was repeated at least three times.

547 Fig. 5 Apoptosis detection in DCs infected by Brucella. DCs were collected and stained by

548 Annexin V/PI at $24 \mathrm{~h}$ post-infection and apoptosis rate was detected by flow cytometry. (A)

549 Annexin V versus PI dot plots graphs. (B) GraphPad shows the result of one representative

550 experiment of the three performed. Quantification of the percentage of Annexin V-positive

551 cells. Bars express the mean \pm SD of duplicates. Data shown are from a representative

552 experiment of three independent experiments. $* \mathrm{P}<0.05$, ** $\mathrm{P}<0.01$, and $* * * \mathrm{P}<0.001$.

553 Fig. 6 Survival capability and replication of Brucella in DCs. DCs were infected with

554 Brucella mutants and Brucella RB51, 2308 at a MOI of 5. At the indicated time points,

555 DCs were lysed, and the bacterial count was quantified by plating serial dilutions on

556 Brucella Agar plates. Three parallel controls were performed at each time point. CFU,

557 colony forming units. 
Figures
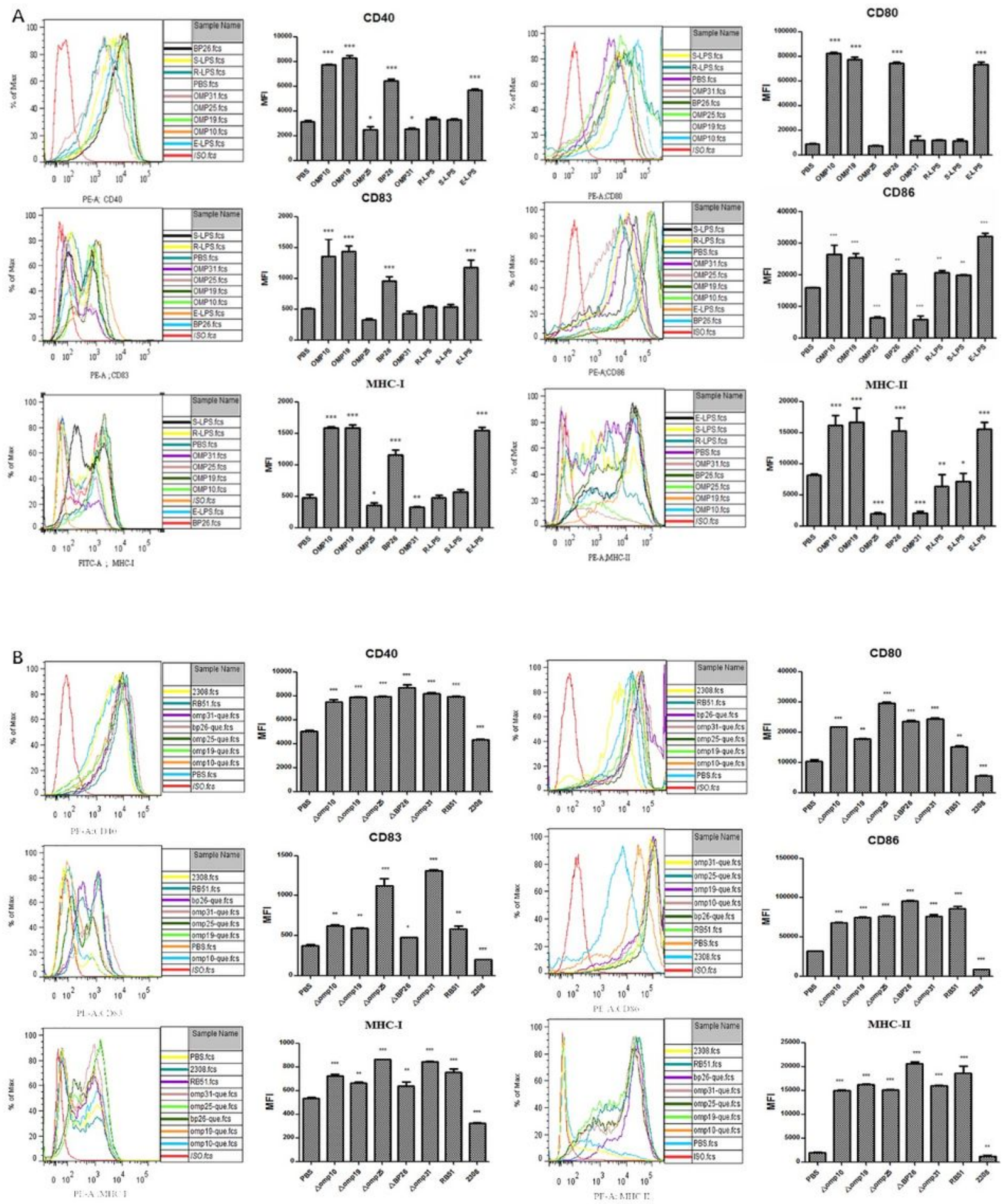

\section{Figure 1}

The effects of Brucella major OMPs and Brucella on surface molecule expression in DCs. DCs were cultured by purified outer membrane proteins (OMPs: OMP10, OMP19, OMP25, BP26, and OMP31) (endotoxin removed), R-LPS, S-LPS, E-LPS(A), or Brucella mutants ( $\Delta$ omp10, $\Delta$ omp $19, \Delta$ omp25, $\Delta$ bp26, 
$\Delta$ omp31), Brucella RB51 and 2308 and PBS for $24 \mathrm{~h}$ (B). DCs were harvested and analyzed by flow cytometry. Cells were stained with fluorescent antibodies against CD80, CD83, CD86, CD40, MHC-I and MHC-II. On the left is a histogram of the presented fluorescence as measured by flow cytometry, and on the right is a histogram of the mean fluorescence intensity (MFI) obtained by statistical analysis. The data are representative of three independent experiments. ${ }^{*} P<0.05$, ${ }^{\star} * P<0.01$, and ${ }^{*} * * P<0.001$. R-LPS: RB51-LPS; S-LPS: 2308-LPS; Escherichia coli LPS: E- LPS; phosphate-buffered saline: PBS.
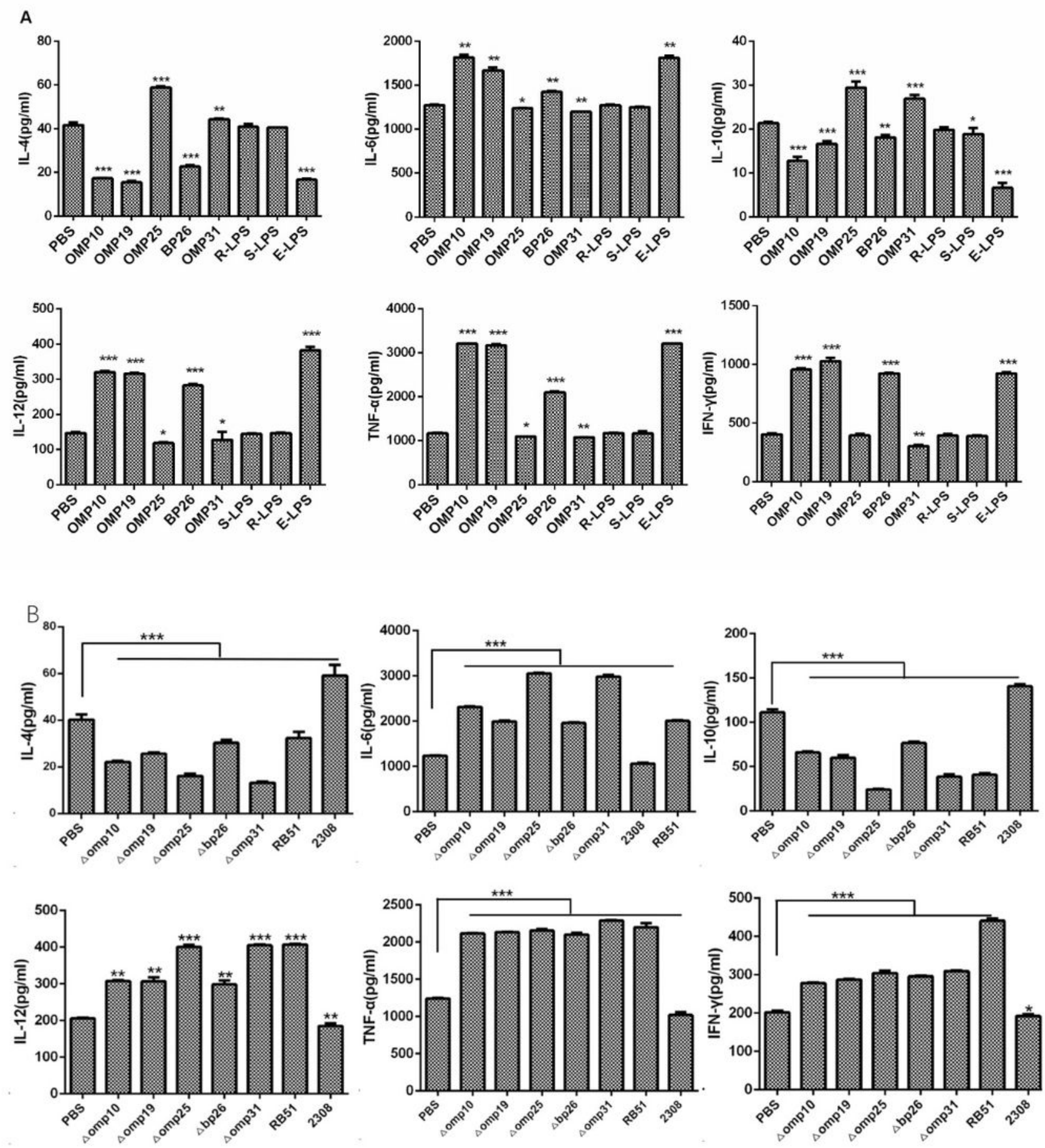

Figure 2 
Cytokine secretion in supernatants of DCs infected with OMPs and Brucella mutants. DCs were cultured with purified OMPs (endotoxin removed), R-LPS, S-LPS, E-LPS (A), or Brucella mutants, Brucella RB51, 2308 and PBS for $24 \mathrm{~h}(\mathrm{~B})$, The culture supernatant was collected and the levels of secreted cytokines IL4, IL-6, IL-10, IL-12, TNF-a and IFN- $\gamma$ quantified by ELISA. Data shown are the means \pm SEMs of three separate experiments. Significance was calculated using the t-test. $* P<0.05$, ** $P<0.01$ and $* \star * P<$ 0.001 .

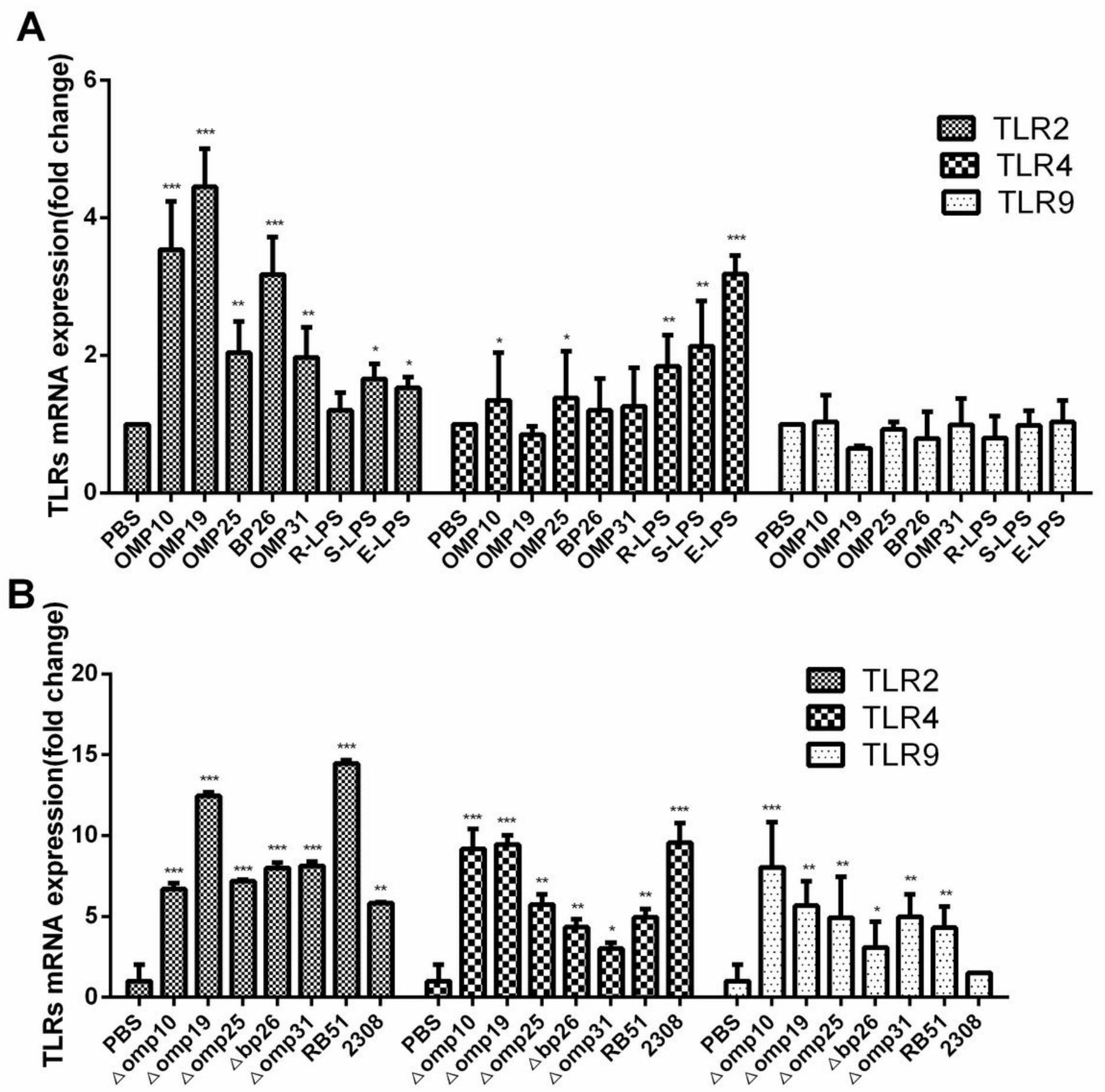

Figure 3 
Effects of OMPs and Brucella mutants on transcription of TLRs mRNA in DCs. DCs were stimulated by OMPs, R-LPS, S-LPS, E-LPS (A), and Brucella mutants, Brucella RB51 and 2308 (B) for $24 \mathrm{~h}$. DCs were then collected, and total RNA was extracted for RT-PCR detection of TLR-2, TLR-4 and TLR-9 mRNA transcription levels. Statistical analysis was performed by the 2- $\triangle C T$ method. Experiments were performed three times in duplicate. ${ }^{*} \mathrm{P}<0.05$, $* * \mathrm{P}<0.01$, and $* * * \mathrm{P}<0.001$.

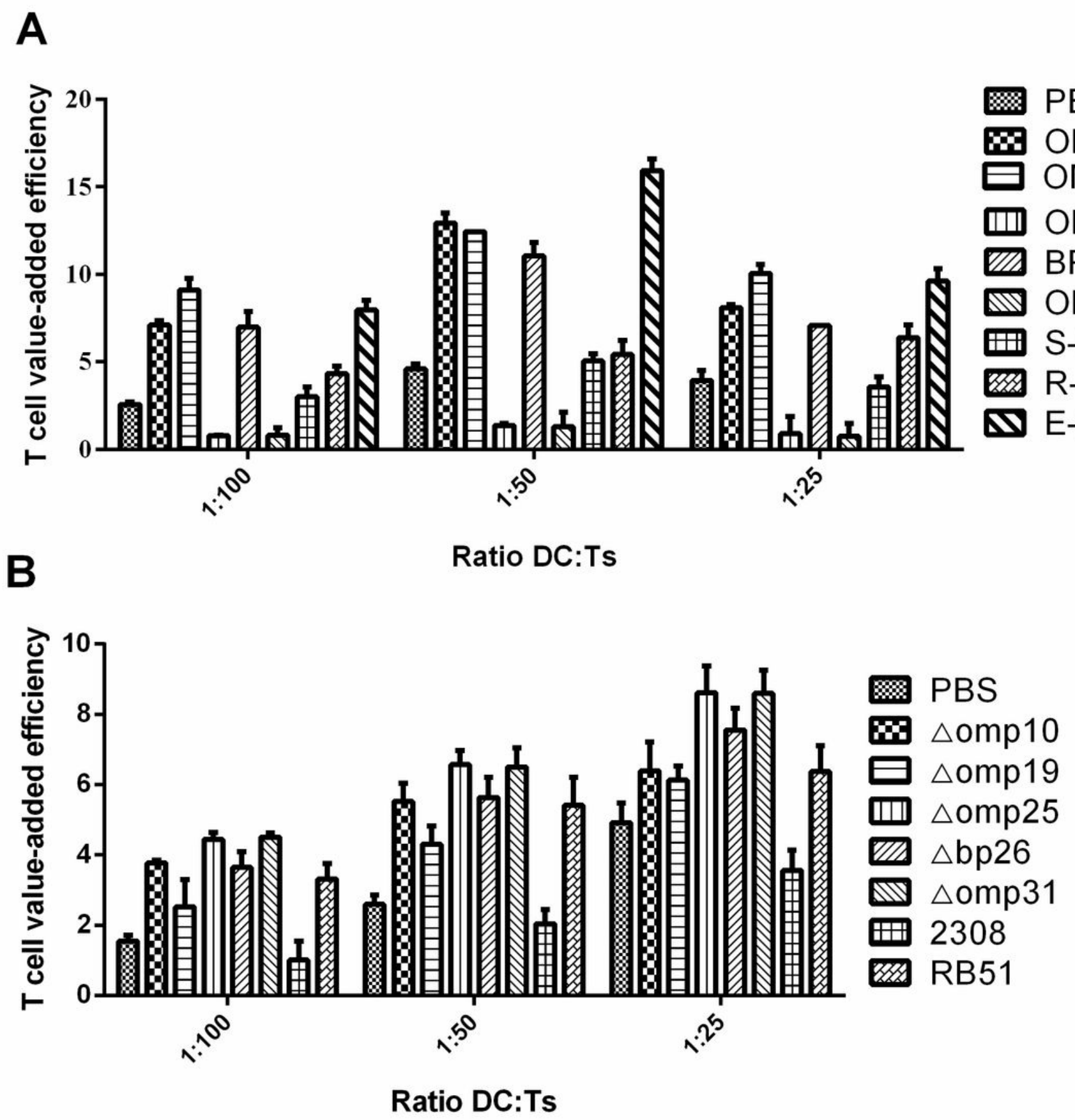

Figure 4

Effects of OMPs and Brucella mutant-stimulated DCs on T lymphocyte proliferation. DCs were stimulated with OMPs, R-LPS, S-LPS, E-LPS (A), or Brucella mutants, Brucella RB51 and 2308 (B) for $24 \mathrm{~h}$, mixed with 
naive $T$ cells and incubated at different concentrations $(1: 25,1: 50,1: 100)$ for $72 \mathrm{~h}$. The proliferation efficiency of T lymphocytes in each group was examined. Each experiment was repeated at least three times.
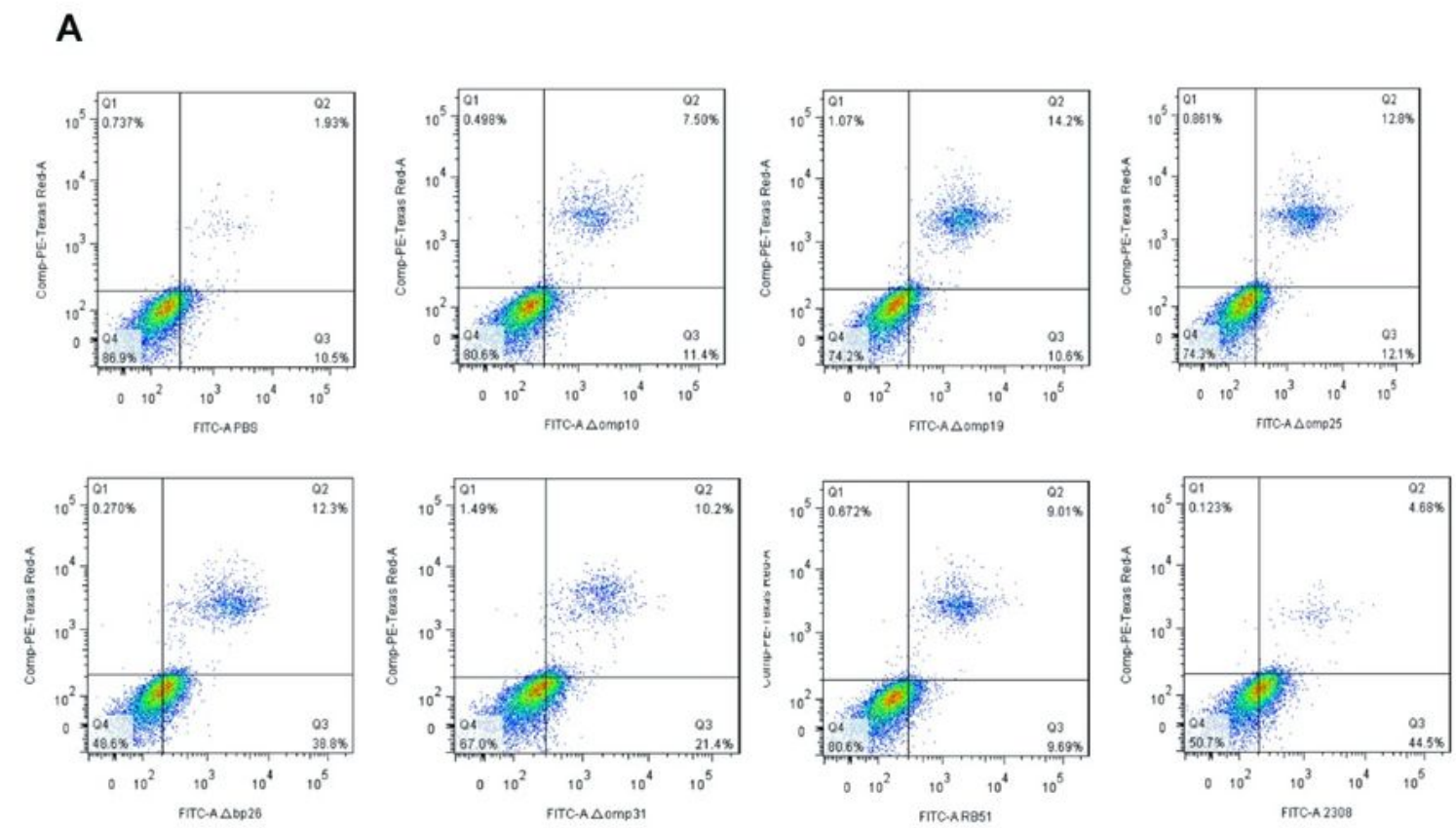

B

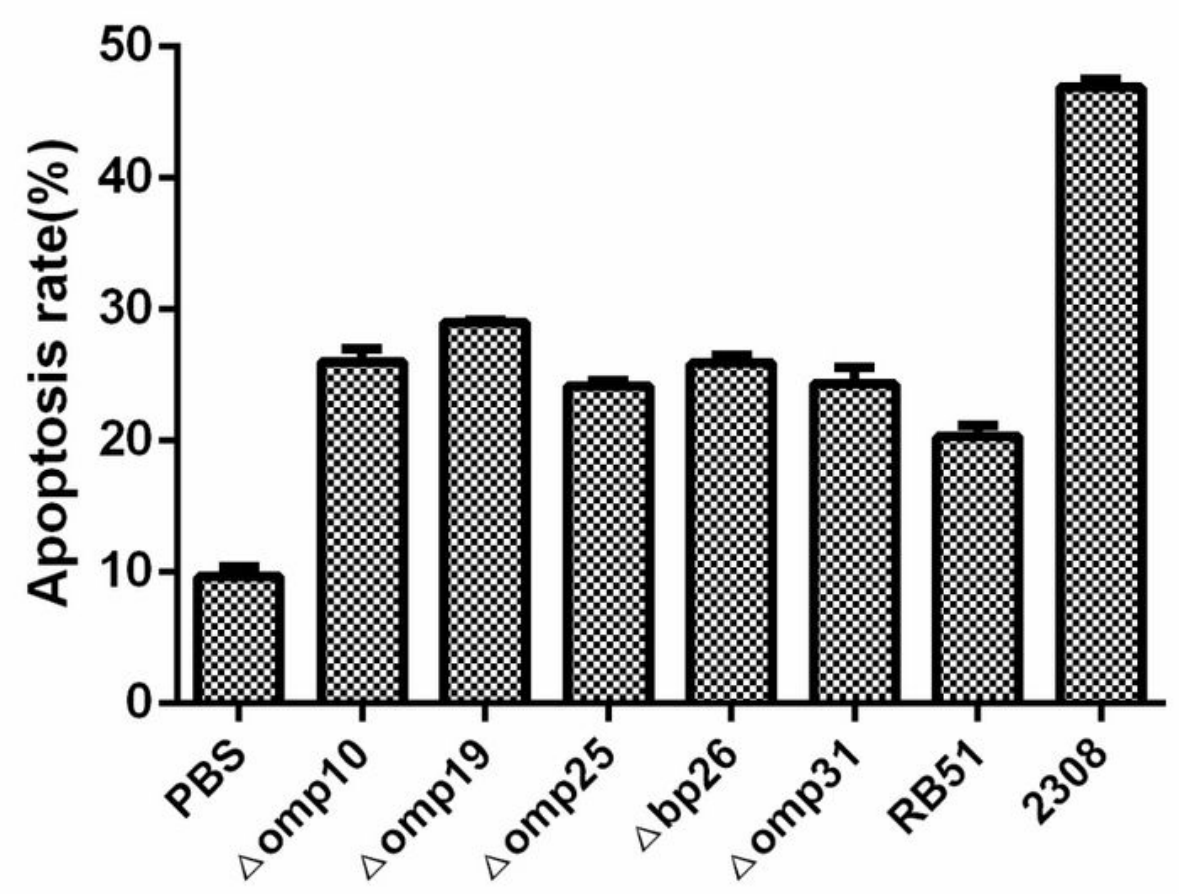

Figure 5

Apoptosis detection in DCs infected by Brucella. DCs were collected and stained by Annexin V/PI at $24 \mathrm{~h}$ post-infection and apoptosis rate was detected by flow cytometry. (A) Annexin V versus PI dot plots 
graphs. (B) GraphPad shows the result of one representative experiment of the three performed.

Quantification of the percentage of Annexin V-positive cells. Bars express the mean \pm SD of duplicates. Data shown are from a representative experiment of three independent experiments. ${ }^{*} P<0.05, * * P<$ 0.01 , and $* * \star P<0.001$.

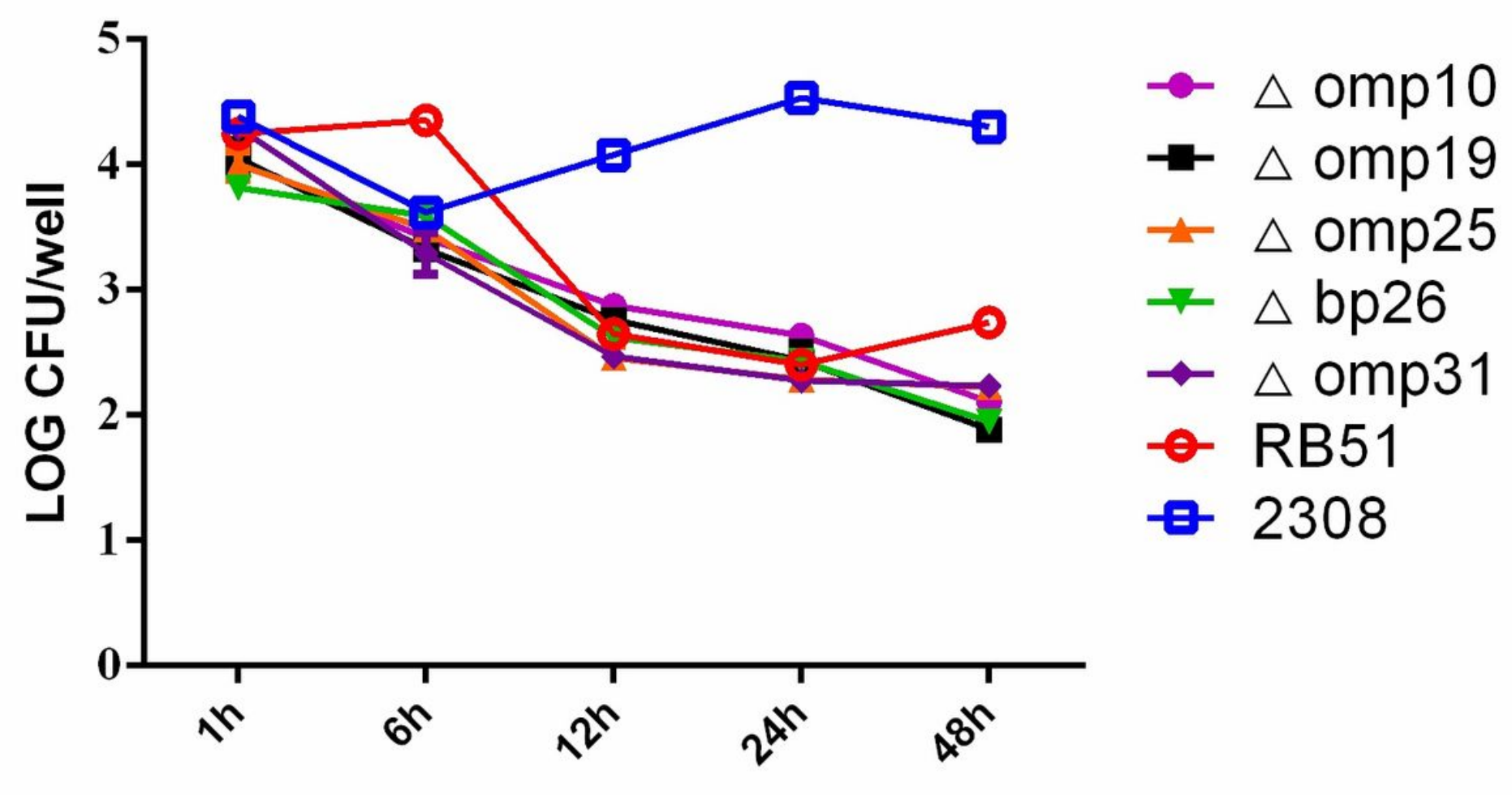

Time (h)

Figure 6

Survival capability and replication of Brucella in DCs. DCs were infected with Brucella mutants and Brucella RB51, 2308 at a MOI of 5. At the indicated time points, DCs were lysed, and the bacterial count was quantified by plating serial dilutions on Brucella Agar plates. Three parallel controls were performed at each time point. $\mathrm{CFU}$, colony forming units.

\section{Supplementary Files}

This is a list of supplementary files associated with this preprint. Click to download.

- Table1.pdf

- TheARRIVEGuidelinesChecklist.pdf 